\title{
A PESQUISA OPERACIONAL SOFT APLICADA À GOVERNANÇA PARA O DESENVOLVIMENTO TERRITORIAL
}

\author{
Leonardo de Moura Perdigão Pamplona
}

Universidade Federal do Rio de Janeiro - UFRJ

Programa de Engenharia de Produção - PEP

Instituto Alberto Luiz Coimbra de Pós-Graduação e Pesquisa de Engenharia - COPPE Centro de Tecnologia - Rua Horácio Macedo, Bloco G, 2030 - 101

Cidade Universitária, Rio de Janeiro - RJ, 21941-450

leonardompp@yahoo.com.br

Marcos Pereira Estellita Lins

Universidade Federal do Rio de Janeiro - UFRJ

Programa de Engenharia de Produção - PEP

Instituto Alberto Luiz Coimbra de Pós-Graduação e Pesquisa de Engenharia - COPPE Centro de Tecnologia - Rua Horácio Macedo, Bloco G, 2030 - 101

Cidade Universitária, Rio de Janeiro - RJ, 21941-450

marcos.estellita.lins@gmail.com

\section{RESUMO}

\begin{abstract}
$\mathrm{O}$ artigo trata dos desafios do desenvolvimento territorial no Brasil, apontados pela literatura, com destaque para os aspectos da governança. Com base no diagnóstico apresentado, são abordados aspectos conceituais, metodológicos e programáticos, baseados no conceito de pesquisa operacional (PO) soft, como proposta para o tratamento ao tema, de forma complementar à abordagem hard da PO.
\end{abstract}

Palavra-chave: Desenvolvimento Territorial; Governança; Multimetodologia.

\begin{abstract}
The article presents the challenges of territorial development in Brazil, pointed out by the literature, with emphasis on the governance aspects. Based on the diagnosis presented, conceptual, methodological and programmatic aspects are discussed, based on the concept of soft operational research (OR), as a proposal for the treatment of the theme, complementary to OR's hard approach.
\end{abstract}

Keywords: Territorial Development; Governance; Multimethodology.

\section{Como Citar:}

PAMPLONA, Leonardo; ESTELLITA LINS, Marcos Pereira. A Pesquisa Operacional Soft Aplicada à Governança Para o Desenvolvimento Territorial. In: SIMPÓSIO DE PESQUISA OPERACIONAL E LOGÍSTICA DA MARINHA, 19., 2019, Rio de Janeiro, RJ. Anais [...]. Rio de Janeiro: Centro de Análises de Sistemas Navais, 2019. 
Um dos maiores desafios para a consolidação do Brasil como Nação desenvolvida é a redução de suas desigualdades sociais e regionais. O presente artigo se propõe a apresentar o tema do desenvolvimento territorial como objeto de análise, a fim de delinear possibilidades de elaboração de políticas públicas com base num diagnóstico das questões que se apresentam com maior relevância segundo a literatura. $\mathrm{O}$ tema da governança tem destaque por sua centralidade no processo de elaboração e execução das políticas públicas.

Adotar um enfoque territorial nas políticas públicas significa considerar o tratamento integrado e sistêmico dos diversos aspectos da política de desenvolvimento: econômicos, sociais, ambientais, culturais e institucionais. Assim, uma política pública robusta deve compreender os diversos espaços, e as relações entre eles, tanto para dentro quanto para fora das fronteiras de um território, conhecendo as especificidades dos atores e seus movimentos, a fim de melhor orientar o processo do desenvolvimento.

Após um breve panorama histórico sobre a constituição do território nacional, incluindo as políticas públicas territoriais mais recentes, serão abordados aspectos conceituais relativos aos desafios apontados para a governança territorial e apontamentos programáticos para debate.

\section{NOTAS SOBRE A FORMAÇÃO DO TERRITÓRIO BRASILEIRO}

A obra clássica do economista Celso Furtado, Formação Econômica do Brasil (FURTADO, 1959: 1987), sintetiza a história da ocupação do território que veio a constituir o nosso país, vinculada a ciclos econômicos de exploração de atividades extrativas voltadas para o mercado externo. "Ilhas" ou "enclaves" que não se conectavam entre si, a exploração do pau-brasil, da cana de açúcar e do ouro foram moldando a ocupação da Bahia até Minas Gerais, sendo as localidades ligadas à exportação as mais dinâmicas, ficando as demais desconectadas daquelas atividades.

Somente na chamada "Era Vargas" o Brasil consolidou o seu caráter urbano-industrial. Os grandes investimentos em transportes e energia ampliaram o comércio interregional, possibilitando a integração dos mercados regionais e uma trajetória de superação da lógica de "arquipélago" característica da formação econômica do país (CANO, 2002). Nas décadas de 1940 a 1960, iniciativas estatais de grande envergadura foram lançadas, como a constituição da Vale do Rio Doce, da Petrobras, da Eletrobras e do BNDES, dentre outras.

A constituição geopolítica do Brasil como grande nação foi iniciada pelo crescimento da região Centro-Sul, em um contexto de vantagens comparativas e competitivas adquiridas historicamente pela região, com base nas externalidades econômicas da economia cafeeira.

A construção da base industrial nacional, favorecida pela capacidade de acumulação e diversificação do complexo cafeeiro paulista, aliada à constituição de um sistema de transportes em torno à região de São Paulo, tendeu a concentrar a produção na Região Sudeste, que chegou a responder, em 1970, por 81\% da atividade industrial, sendo que apenas São Paulo era responsável por 58\% do total. As distâncias das demais regiões em relação aos centros dinâmicos do país, ampliadas pela precariedade de infraestrutura, dificultavam bastante a sua ocupação e integração (CAMPOLINA, 2002). As políticas de crescimento baseadas na industrialização, contexto no qual as políticas sociais e regionais eram consideradas como ações compensatórias, resultou na construção de um país que se tornou, por um lado, a oitava economia do mundo e, por outro, um dos casos mais graves de desigualdades (BACELAR, 2003).

Pode-se dizer que a integração produtiva do território nacional foi construída com base em um planejamento elaborado no nível federal, tendo como força motriz a expansão da economia paulista, e vinculando as demais regiões à dinâmica observada no polo concentrador (BACELAR, 1999). Além disso, a despeito de uma tendência de desconcentração observada em nível macrorregional, levada a cabo pelas inciativas mencionadas anteriormente, dentro das regiões observou-se aumento da concentração de renda (por exemplo, Manaus na Região Norte, Salvador e Recife na região Nordeste).

A partir da década de 1980, por conta da crise econômica e da crise do modelo estatista de intervenção na economia conforme vinha sendo implementado, as políticas regionais perderam importância.

O receituário que passou a vigorar na década de 1990 focava na atração de investimentos com base nas condições de competitividade dos territórios, questionando e enfraquecendo o papel do Estado nacional na promoção do desenvolvimento. De um extremo ao outro, passou-se de uma abordagem de planejamento nacional do desenvolvimento regional, ainda que em âmbito macrorregional, para um paradigma de desenvolvimento local sem a mediação da esfera nacional, fazendo ligação direta dos territórios com os mercados, especialmente os internacionais, no contexto de uma idealizada globalização.

Isso configurou a (re)emergência de uma estratégia de criação de "ilhas de dinamismo" envoltas de pobreza e estagnação e a fragmentação do mercado interno nacional, contribuindo para um retrocesso no processo de integração do país (BACELAR, 1999).

As estratégias implementadas em geral na década de 1990 - os programas “Avança Brasil" e "Brasil 
em Ação" tinham esse objetivo - eram focadas na especialização em atividades primário-exportadoras e na infraestrutura necessária para o escoamento dessa produção.

Esse direcionamento acabou por fomentar um processo de reconcentração produtiva, pois os investidores, de modo geral, tendem a aplicar seus recursos nas regiões mais dinâmicas, deixando à margem as regiões com menor potencial.

A situação favoreceu um cenário de disputa entre os entes federados, por meio de artifícios como a chamada "guerra fiscal", na qual se busca criar condições de atratividade de investimentos via redução de tributos - o que contribuiu para uma crise adicional, que chegou naquele momento às relações federativas.

\section{POLÍTICAS DE DESENVOLVIMENTO TERRITORIAL NO SÉCULO 21}

Em contraposição ao cenário fragmentador da década de 1990, o início do século 21 viu florescer uma discussão promovida por atores locais ativos que buscavam se articular para a elaboração de estratégias soberanas de desenvolvimento local e regional. Uma das bases conceituais dessas estratégias de reação aos processos fragmentadores é a do desenvolvimento sustentável, que, além de reforçar a dimensão socioambiental, enfatiza a necessidade de afirmação das identidades locais, ameaçadas pelas tendências de vinculação subordinada dos territórios à lógica do mercado global.

Ao mesmo tempo em que a abordagem territorial emergente se propunha a surgir de dentro dos próprios territórios, a partir das especificidades e potencialidades próprias de cada um, a ideia do protagonismo de uma instância nacional voltava a se fortalecer, como ente capaz de coordenar o diálogo e a integração multiescalar de um projeto estratégico.

Uma referência foi a política regional realizada pela União Europeia, cujo objetivo é gerar desenvolvimento local em prol da coesão regional, o que além das questões econômicas também é uma questão de segurança para os países membro.

Os avanços teóricos e metodológicos no Brasil também observaram o debate, originado na Europa, em relação aos conceitos de rural e urbano. O conceito de rural como área eminentemente agrícola, entendido como ultrapassado, deu lugar ao conceito de desenvolvimento territorial. Assim, esse novo conceito preconizou a necessidade da existência de um conjunto de políticas integradas que diversifique a infraestrutura e a economia das zonas rurais, vistas para além da agricultura, incluindo as cidades pequenas e médias do interior com baixa densidade urbana.

Dessa maneira, o objetivo das políticas voltadas ao desenvolvimento das zonas rurais também é proporcionar maior equilíbrio na distribuição da atividade econômica e da população, ao gerar atratividade em áreas menos densamente povoadas, dessa maneira reduzindo as pressões existentes nas grandes cidades.

A abordagem territorial também avançou em relação às políticas de desenvolvimento regional tradicionais, em geral voltadas para escalas espaciais maiores. A ideia de tratar o desenvolvimento a partir de escalas menores visa atender de uma melhor maneira a complexidade inerente aos territórios e suas especificidades no âmbito micro. Assim, novos recortes territoriais foram sendo trabalhados a fim de conferir maior eficácia às políticas públicas.

O caso da Terceira Itália foi uma das primeiras referências no estudo do desenvolvimento territorial com base em redes relacionais e aglomerações produtivas (PUTNAM, 2002), em linha com os conceitos de distrito industrial (BECATTINI, 1990) e, posteriormente, de cluster (PORTER, 1993), que mais tarde deram, no Brasil, origem ao conceito de arranjos produtivos locais - APLs (MATOS ET ALLI, 2017).

\section{POLÍTICAS PÚBLICAS TERRITORIAIS: EXPERIÊNCIAS E DESAFIOS}

A Constituição Federal do Brasil (BRASIL, 1988) contempla alguns dispositivos relacionados ao desenvolvimento regional, destacando-se: artigo $3^{\circ}$, que trata de missão de "erradicar a pobreza e a marginalização e reduzir as desigualdades sociais e regionais"; artigo 43, que prevê que "a União poderá articular sua ação em um mesmo complexo geoeconômico e social, visando a seu desenvolvimento e à redução das desigualdades regionais"; artigo $174^{\circ}$, definindo que "a lei estabelecerá as diretrizes e bases do planejamento do desenvolvimento nacional equilibrado, o qual incorporará e compatibilizará os planos nacionais e regionais de desenvolvimento", dentre outros.

$\mathrm{O}$ artigo $165^{\circ}$, por sua vez, estabeleceu a necessidade de realização dos planos plurianuais (PPA) e, já na formulação, colocava a necessidade de conter um caráter regional.

$\mathrm{O}$ advento do PPA não teve facilidades de implementação efetiva imediata, tendo avançado lentamente como promotor da abordagem territorial, em especial diante das adversidades oriundas da crise econômica dos anos 1980 e 1990. 
Em 2006, o Ministério do Planejamento, Orçamento e Gestão desenvolveu o Estudo da Dimensão Territorial para o Planejamento (MPOG, 2006), com o objetivo de subsidiar a elaboração do PPA 2008-2011, apresentando um novo olhar sobre o território nacional, que considerava a diversidade econômica do país e os diversos polos regionais compostos por cidades médias que delineavam grandes espaços homogêneos, além de uma nova proposta de macrorregionalização.

Esse trabalho ainda não teve o aproveitamento do potencial apresentado, tanto por questões políticas quanto por questões gerenciais no contexto do Governo Federal.

O tema do desenvolvimento regional também foi objeto de elaboração e implementação de diversas políticas públicas, tanto em nível federal quanto por meio de programas estaduais de promoção de atividades econômicas em regiões menos dinâmicas.

Estudo com mais de 60 experiências em esfera estadual e federal (FAVARETO, 2009), aponta que essas políticas, em geral, apesar da preocupação com uma visão territorial, incluindo a constituição de instâncias participativas para a gestão, tinham caráter eminentemente setorial. Ainda que a abordagem territorial possa parecer, em princípio, apenas uma "inovação retórica", representam um esforço inicial cujo caminho até o amadurecimento é longo e precisa ser trilhado com persistência, considerando os desafios de superação na cultura organizacional do Estado brasileiro e o pouco costume da população a processos de participação social.

Das experiências analisadas por Favareto, destacam-se os programas do Ministério da Integração Nacional (MI) e do Ministério do Desenvolvimento Agrário (MDA) que, apesar das limitações, propunham ações mais amplas e articuladas.

Cada um desses Ministérios elaborou e desenvolveu suas próprias políticas, ainda que tivessem várias sobreposições e semelhanças, em especial a base conceitual da integração de políticas públicas e a participação social por meio de conselhos e colegiados territoriais. A Política Nacional de Desenvolvimento Regional (PNDR-MI), com diversos programas específicos, e o Programa Territórios da Cidadania (PTCMDA) foram os mais destacados, este tendo apresentado um avanço organizacional importante ao definir como instância de coordenação e articulação a Casa Civil, órgão com capacidade de melhor orientar a integração das políticas.

Além das iniciativas federais, diversas experiências em nível estadual foram empreendidas, bem como estudos de caso relativos a algumas delas, que convergem em grande medida em relação aos resultados, dificuldades e recomendações de aprimoramento (BUARQUE ET AL, 2008; PAMPLONA, 2011; MONTEIRO NETO ET ALLI, 2017). As conclusões dos estudos a respeito da implementação e resultados dessas políticas giram em torno de três questões fundamentais.

A primeira questão trata das dificuldades de ordem político-institucional. As questões políticas, como mencionado, têm a ver com a falta de estímulos ao conjunto dos atores relevantes para que contribuam com o processo de planejamento territorial, que muitas vezes mantém invisíveis setores historicamente excluídos, desequilibrando a representatividade nas instâncias deliberativas.

A ainda incipiente cultura de participação também dificulta o alcance de uma visão sistêmica. A visão setorialista, ou corporativista ou individualista faz com que o diálogo sobre o desenvolvimento territorial se transforme em uma soma de demandas específicas desarticuladas, e os conflitos de interesses tendem a favorecer os setores tradicionalmente mais fortes, sendo corriqueira a captura das instâncias deliberativas pelo poder público.

Essas questões políticas, que incluem disputas dentro do próprio setor público, nas diversas esferas, por protagonismo na implementação das ações (consequentemente, pelo controle dos recursos), também contribuem para um planejamento viesado, a fragmentação e sobreposição das políticas públicas no território, dificultando a articulação efetiva das mesmas.

Ainda há muito o que aprimorar em termos de instrumentos regulatórios adequados para dar conta da complexidade da abordagem territorial, considerando as múltiplas escalas, as relações federativas e as regras de gestão dos recursos públicos, bem como na capacidade institucional das instâncias deliberativas territoriais, em especial uma instância nacional politicamente empoderada e com capacidade real de coordenação.

Nem mesmo a chegada de grandes empreendimentos produtivos tem sido capaz de promover dinâmicas e encadeamentos que enraízem e frutifiquem o desenvolvimento nos territórios no entorno desses projetos, por conta das dificuldades apresentadas.

Essas questões podem ser relacionadas aos vícios de origem e à dificuldade de superação da cultura política ainda vigente no Brasil, tanto no que diz respeito às forças que se movimentam para dificultar a implementação das políticas públicas quanto ao próprio processo embrionário em que as mesmas se encontram.

A segunda questão, ligada à primeira, enaltece, em geral, o caráter inovador das políticas territoriais, por suas premissas de articulação e participação social, consideradas, juntamente com a visão territorial do desenvolvimento, como aspectos fundamentais para o sucesso das políticas públicas no século 21 (EVANS, 2010). Pondera-se, naturalmente, a respeito da necessidade de uma perspectiva de longo prazo para que se 
superem as dificuldades inerentes à cultura política e social ainda vigente e as políticas territoriais se consolidem.

A terceira questão é a constatação de que as experiências mais exitosas, ainda que com abrangência espacial limitada, estão diretamente correlacionadas com a qualidade e a intensidade dos laços de relacionamento institucional nos territórios.

\section{GOVERNANÇA COMO ASPECTO CENTRAL PARA O APRIMORAMENTO DAS POLÍTICAS DE DESENVOLVIMENTO TERRITORIAL}

Com base no exposto, se destaca como basilar o tema da governança, aqui definida como o conjunto de padrões de comunicação e relacionamento entre os atores presentes nos territórios, em prol de consensos mínimos a respeito da agenda estratégica adequada à realidade de cada lugar, também levando em consideração a interação com territórios contíguos e escalas espaciais mais abrangentes.

Os desafios do século 21, com a crescente complexidade e interatividade, pressupõe instituições robustas e competentes no centro da matriz institucional de um país a fim de cumprir o papel de "expansor de capacidades", por meio da provisão eficiente de bens coletivos para toda a população, como saúde, educação e mobilidade, pré-requisitos para um bom desempenho social e econômico.

Uma vez que a capacidade de tomar decisões é uma das mais importantes capacidades humanas, processos de participação e deliberação públicos devem ser entendidos como partes constitutivas dos fins do desenvolvimento. A democracia pode ser considerada como uma "meta-instituição" que promove instituições de alta qualidade, que por sua vez estimulam o desenvolvimento (RODRIK, 1999).

Para além da democracia participativa, a chamada democracia deliberativa se coloca como alternativa mais estruturada para definir adequadamente quais os fins desejados no contexto de uma sociedade cada vez mais complexa (SEN, 2005).

Zaoual (2006) propõe um novo humanismo, baseado no resgate de uma ética da solidariedade e da cooperação perdidas no âmbito do paradigma da competitividade individualista. O autor enxerga os territórios como sítios simbólicos de pertencimento, a partir dos quais podem se desenvolver um empreendedorismo e um desenvolvimento situados, a serem definidos pelos atores locais com base nas necessidades e perspectivas específicas de cada território, sem seguir um modelo previamente definido do que seja desenvolvimento.

A questão que se coloca é como ampliar a compreensão "espacial" do setor privado para além do seu negócio estrito, entendendo o entorno geográfico como parte de sua responsabilidade; da burocracia pública para além da sua atribuição setorial, a fim de que compreenda e pratique a integração das políticas públicas; e da população para se apropriar do próprio processo de desenvolvimento, fortalecendo o senso de pertencimento e corresponsabilidade pela coletividade. E isso remete a questões culturais, que precisam ser enfrentadas a fim de superar alguns modelos mentais vigentes.

A construção cultural, ou padrão de comportamento, predominante na sociedade atual é calcada na premissa de que a busca do bem-estar individual promove o bem-estar coletivo.

Parece ter se difundido uma compreensão de que o bem-estar individual prescinde de um olhar sistêmico, e esse bem-estar desconsidera o outro, de certa maneira autorizando a opressão ou exploração de indivíduos que fazem parte do mesmo sistema, e a exploração dos recursos naturais como se fossem infinitos.

Dessa maneira, se no sistema há indivíduos em situação desfavorável, mesmo os que se locupletam dessa situação não estão usufruindo da melhor condição possível, pois aquele desequilíbrio entre seus membros está sujeito a gerar degradação ambiental e social, violência, dentre outras ineficiências.

Griffin (2002) entende essa cultura como um padrão de comunicação originado nas interações em nível micro que emergem como processo coletivo em âmbito macro de organizações e sociedades. É importante trabalhar para que cada ator do sistema compreenda melhor não apenas o que é esse sistema emergente, mas também seu papel no mesmo, para que assim possa contribuir para o fortalecimento e emergência de padrões de produção, consumo e relacionamento humano mais harmoniosos e sustentáveis.

Segundo esse autor, em geral as pessoas, ainda baseadas numa visão individualista, se veem como independentes do sistema. Dessa forma, tendem a terceirizar a responsabilidade das coisas que não as agradam para o sistema, como se o este fosse uma entidade dotada de consciência própria, e não o resultado da soma dos vetores dos relacionamentos em nível micro, do qual todos fazem parte. Assim, se eximem de tomar atitudes necessárias, pois não se veem capazes de influenciar o sistema.

À medida que a sociedade avançou, a ampliação da complexidade e dos conflitos inerentes a esse processo de evolução vem impondo limites ao método científico moderno, muito centrado em aspectos quantitativos e modelagem matemática, em busca de soluções ótimas, porém com baixo número de variáveis levadas em consideração.

Conforme Estellita Lins e Estellita Lins (2018), trata-se de um modelo insuficiente para lidar com 
processos decisórios complexos, nos quais processos sociais interagem profundamente com processos psicológicos individuais. Porém, os padrões de comportamento e comunicação ainda são muito vinculados esse tipo de matriz filosófica, na qual uma das principais características é a compartimentalização do pensamento, o que ainda restringe o avanço de uma percepção mais sistêmica.

Nesse sentido, as ciências da gestão vem desenvolvendo métodos que favoreçam uma visão mais sistêmica desses problemas, para que sejam mais bem estruturados e, consequentemente, melhor gerenciados.

A vertente empírico-analítica é um dos três paradigmas existentes na literatura de ciências da gestão e pesquisa operacional (ESTELLITA LINS, 2018c), calcada numa visão de causa e efeito direto entre os fenômenos.

Para além dessa vertente empírico-analítica, de caráter quantitativo e objetivo, devemos levar em consideração também os aspectos qualitativos e subjetivos, como a interação social humana nos processos decisórios, que vai além da causalidade e introduz aspectos subjetivos à análise, e a possibilidade de, por meio de uma autoconsciência crítica, alcançar a emancipação de restrições de ordem institucional, cultural e das relações de poder, ampliando os pontos de vista para além do que os padrões culturais tentam nos impor como natural.

\section{PESQUISA OPERACIONAL SOFT E MULTIMETODOLOGIA}

No campo da pesquisa operacional, o debate foi, inicialmente, tratado nos termos de um aparente embate entre pesquisa operacional hard e soft. Atualmente, está consolidado na literatura que tratam-se de métodos complementares de aspectos quantitativos e qualitativos, ambos igualmente necessários para a abordagem de problemas reais.

Em geral, indivíduos, e organizações (consideradas como conjuntos de indivíduos), por conta dos padrões de comportamento arraigados, ainda tendem a reprimir as contradições e paradoxos inerentes à natureza humana, dado o incômodo que os mesmos representam.

Assim, um movimento de fuga é o mais comum de acontecer, com o objetivo de manter ao menos uma aparência de coerência e consistência no discurso. Esse padrão de comportamento limita uma visão completa dos problemas, e a estruturação de soluções para os mesmos que, por ser parcial, provavelmente não vai atender a real necessidade de uma dada situação.

Estellita Lins (2018a) propõe, com base em Miron-Specktor et al (2011), que integrar demandas conflitantes pode aumentar a criatividade, e que "na gestão cotidiana das relações organizacionais é importante assumir uma atitude de discernimento sobre valores a preservar e oportunidades de mudanças evolutivas, normalmente decorrentes da integração de perspectivas individuais, e não de um plano preconcebido por um (conjunto de) especialista(s) em particular".

Se do ponto de vista individual ainda há dificuldades em compreender o caráter múltiplo da personalidade humana, conforme demonstram avanços no campo da psicologia, como os estados do ego (FEDERN, apud ESTELLITA LINS, 2018a), do ponto de vista organizacional também há problemas em encarar diferentes visões de mundo quando da elaboração e elaboração de diagnósticos e planejamentos. Segundo Estellita Lins (2018b), "parece que o medo inconsciente de perder sua identidade, seu papel adaptado ao ambiente em que vive, é o principal fator que inibe esta percepção ampliada". A compartimentalização do conhecimento restringe, também, uma visão mais complexa, que integre diversos tipos de abordagens.

Portanto, a gestão do contraditório e paradoxal é fundamental para um melhor encaminhamento de um problema. A diferenciação dos diversos perfis existentes é importante, porém é necessário integrá-las a fim de melhor representar e tratar a realidade, o que não é uma tarefa simples. Estellita Lins (2018a) destaca a importância de um ambiente confiável, que estimule a espontaneidade, para uma adequada integração de diferenças, bem como a capacidade de transformar a percepção sistêmica em processos operacionais.

Lewis et al. (2014) apresenta alguns típicos paradoxos organizacionais, como flexibilidade X controle; autocracia X democracia (ou regulação hierárquica X regulação distribuída); objetivos financeiros $\mathrm{X}$ objetivos sociais; e visão local X visão global.

Segundo as autoras, o padrão de comportamento das empresas é a utilização da teoria da contingência, por meio da qual os gestores escolhem, por meio de análise de prós e contras, entre uma opção ou outra.

Porém, as mesmas propõem, sob uma perspectiva paradoxal, que a reflexão deve se dar sobre como é possível engajar duas ou mais opções aparentemente ou superficialmente contraditórias, pois confrontar as tensões é a maneira mais indicada para o alcance da sustentabilidade de longo prazo, nos diversos sentidos possíveis para o termo. Assim, considerando as tensões inerentes à vida organizacional, preconizam que os líderes devem estar atentos para que as respostas a essas tensões não sejam defensivas, ou seja, que não se ocultem as tensões sob nenhum pretexto, mas sim para que as respostas sejam estratégicas, assumindo e 
integrando as tensões.

Para isso, é preciso um esforço deliberado de auto-observação para o autoconhecimento (organizacional, quando tratarmos de coletivos), a fim de perceber a realidade de uma maneira mais complexa, com todas as suas inconsistências. A fuga das contradições, e o conforto psicológico percebido, contribuem para postergar a solução da questão em jogo. A omissão de parte da realidade, nesse sentido, não contribui para alterá-la de maneira efetiva.

Continua sendo um desafio para os indivíduos e organizações o processo de autoexame, justamente pela dificuldade em lidar com aspectos que contrariem seus valores sociais (como no caso da proeminência do interesse pessoal em detrimento do coletivo) ou, quando se trata de organizações, perfis não alinhados com o poder dominante. A postura crítica é fundamental para que se possa vislumbrar os limites e possibilidades de evolução, e para isso o reconhecimento da complexidade é uma premissa para que diagnóstico e planejamento sejam construídos da melhor maneira possível (MINGERS, 2006).

Bohm (2005) propõe que a postura dialogal passa pelo reconhecimento e aceitação da diversidade sem julgamento, que o autor conceitua como "suspensão de pressupostos", ou seja, um processo de desapego das posições pessoais a fim de possibilitar a síntese com visões diferentes, seja do ponto de vista interno ou externo ao indivíduo. $\mathrm{Na}$ sociedade atual, a cada vez maior magnitude dos problemas sociais explicita a necessidade de ampliar o foco de análise para melhor definir as causas e intervenções necessárias para solucioná-los.

O aprimoramento do processo de tomada de decisão passa, assim, pela adoção de uma postura denominada por Estellita Lins e Estellita Lins (2018) de introspectiva ou metacognitiva (pensar sobre o pensamento), ou seja, um esforço consciente de tomada de conhecimento dos diversos aspectos do problema ou questão em tela, especialmente aqueles que possivelmente são desconhecidos e ignorados.

Os autores citam diversas pesquisas que vão no sentido de indicar que "a tomada de decisão humana tem demonstrado que as escolhas das pessoas em diferentes domínios são afetadas por tendências, que as levam a cometer erros graves ou, menos dramaticamente, a tomar decisões que estão longe de serem as melhores. Esses preconceitos são produzidos por tendências enganosas na representação das informações sobre as opções disponíveis; por cognição e afetividade heurística; por falhas de ativar processos de controle inibitórios necessários para tornar-se capaz de avaliar a adequação dos julgamentos impulsivos ou intuitivos e tendências de resposta para, se for o caso, neutralizá-los" (Idem).

Nesse processo, é pertinente estudar como a mentira e o autoengano exercem papel relevante na omissão e acobertamento de determinados aspectos da situação, a fim de manter a autoestima e a integridade do ego. É possível mentir para si mesmo como um mecanismo de defesa, "para proteger-se do perigo de uma crença ameaçadora e para manter uma imagem satisfatória de si” (ANOLLI, 2004, apud ESTELLITA LINS, 2018a).

Assim, necessitamos desenvolver uma mente inconsciente para que a verdade ou parte dela seja ocultada de nós mesmos.

Os paradoxos tratados acima, contidos em Estellita Lins (2018a), quais sejam, diversificação versus integração; parte versus todo; multiplicidade versus identidade e autoengano versus metacognição, ao serem trabalhados no campo da pesquisa operacional soft, abrem caminho para a adoção de metodologias múltiplas no tratamento dos problemas complexos. Considerando que diversos aspectos da realidade devem ser trazidos à luz, é natural que cada um deles seja mais bem examinado por um método específico que melhor o aborde, o que pressupõe a multimetodologia.

Segundo Mingers (2006), devem ser levados em consideração os aspectos material, pessoal e social, nas diferentes fases de uma pesquisa (apreciação, análise, avaliação e ação), para uma adequada abordagem metodológica, o que denota a complementaridade entre modelos hard e soft. Assim, podem ser definidas diferentes metodologias para cada fase do processo investigativo, a depender principalmente do caso real e das demandas dos usuários, cuja interação com o pesquisador é parte fundamental para a estruturação do problema em questão.

\section{UMA METODOLOGIA PARA ESTRUTURAÇÃO DE PROJETOS DE DESENVOLVIMENTO TERRITORIAL}

O laboratório PSIGMA, da COPPE/UFRJ, desenvolveu uma ferramenta denominada CHAP2 (acrônimo de Complex Holografic Assessment of Paradoxical Problems, ou Avaliação Complexa Holográfica de Problemas Paradoxais), que se propõe a contribuir com o desenvolvimento do paradigma emancipatório (ESTELLITA LINS, 2018c), conforme já mencionado, dado seu embasamento na gestão dos processos da mente humana.

O CHAP2 é uma ferramenta que contempla as questões elencadas relativas à necessidade de 
integração de diferentes aspectos e pontos de vista sobre um determinado problema de pesquisa. Isso é feito por meio da elaboração de mapas metacognitivos que, pela sua característica de estruturar percepções de diferentes agentes sobre um dado sistema, facilitam a "representação e comunicação do conhecimento, muitas vezes implícito, usado no processo decisório" (idem).

Uma premissa importante é que a metodologia não pode ser implementada de forma hierárquica sem que haja um processo consistente de conscientização dos agentes operacionais sobre seu processo e princípios norteadores. Nesse sentido, necessariamente o CHAP2 é uma metodologia participativa.

A metodologia contempla uma fase inicial de caracterização do sistema "real", por meio da elaboração de um mapa inicial da situação problema com base na visão de "agentes privilegiados", especialistas sobre o tema em tela.

Em seguida, define-se um grupo maior de agentes representativos do problema em análise para serem entrevistados, tendo como premissa a perspectiva de amplitude de visões de mundo acerca do problema, suas possíveis causas e soluções.

Após um processo de orientação desses agentes para uma adequada compreensão da metodologia, são realizadas as entrevistas, cujo objetivo é elaborar mapas metacognitivos compostos pela visão individual de cada entrevistado.

Para além de um conceito cognitivo ligado a estruturas técnicas e processos estabelecidos, um mapa metacognitivo tem como diferencial o favorecimento de uma percepção ampliada do problema em tela, admitindo as divergências e polaridades entre diferentes percepções da realidade, buscando integrar ao invés de suprimir os eventuais conflitos.

Após a elaboração dos mapas individuais de conhecimento, estrutura-se, preferencialmente, de forma participativa junto aos entrevistados, um mapa conceitual, que abarca as perspectivas entre as quais há convergência, e um mapa paradoxal no qual se explicitam as divergências, buscando compreender suas causas e possivelmente apontando caminhos possíveis de melhorias.

Com base nesse trabalho de consolidação, inicia-se a articulação dos resultados do mapeamento do problema em modelos formais, indicadores e processos a serem implementados no problema em tela. A etapa final do ciclo após identificação e implementação de ações viáveis, é o monitoramento dos indicadores definidos na etapa anterior. Nesse caso, deve-se observar que a validação dos resultados em processos complexos vai além de uma abordagem meramente técnica, uma vez que os impactos sobre os diversos segmentos sociais abarcados pelas políticas públicas implementadas.

Em síntese, a aplicação do CHAP2 na estruturação de processos de governança em territórios pode auxiliar a convergência de propósitos diversos, com base na promoção de uma visão sistêmica.

\section{PROPOSTA DE APLICAÇÃO PRÁTICA PARA FUTURAS PESQUISAS}

Tomando como base o território nacional, composto pela articulação de suas diversas partes em um sistema organizado em diversas escalas geográficas, cada qual com sua especificidade e potencialidade, o desafio que se coloca é como constituir uma teia produtiva e social bem conectada, na qual fluxos produtivos espraiem inovação e emprego em maior qualidade e quantidade.

Como outra fonte de apoio ao processo, propostas contidas no Estudo da Dimensão Territorial para o Planejamento e no estudo das Regiões de Influência das Cidades, elaborado pelo Instituto Brasileiro de Geografia e Estatística (IBGE, 2007), propõem repensar a organização federativa brasileira como uma rede de cidades, definindo hierarquias entre espaços dadas pelos fluxos econômicos e sociais.

A compreensão, o resgate e atualização sobre esses fluxos são fundamentais para o planejamento de uma estratégia nacional de desenvolvimento regional e territorial, por meio da promoção de centralidades antigas e novas que espraiem processos de desenvolvimento ao longo do território nacional.

Avançando em uma proposição de intervenção em territórios a serem estudados, entende-se que é importante a elaboração de uma ferramenta computacional de inteligência de negócios, com forte organização de dados das mais diversas naturezas, que permita ampliar o conhecimento das dinâmicas relacionais, redes, conexões e potencialidades econômicas dos atores sociais presentes em cada território.

Com base nessa ferramenta, oportunidades poderão ser mais bem identificadas e estratégias de fomento a atividades produtivas e oferta de serviços públicos poderão ser elaboradas de forma mais racional, considerando as necessidades numa escala territorial adequada, e um sistema articulado que promova maior circulação de bens e serviços por esses territórios, a fim de fortalecer o mercado interno. $\mathrm{O}$ resgate de matrizes insumo-produto mais robustas, auxiliadas por tecnologias de informação, poderá trazer insumos para a (re)localização de empreendimentos e infraestruturas, a fim de proporcionar um melhor ordenamento produtivo no território nacional.

Ferramentas de análise de redes sociais poderão identificar padrões e vínculos a serem criados e/ou 
fortalecidos. Com base nesse mapeamento, a aplicação da metodologia CHAP2 pode, por sua vez, apoiar a construção da convergência estratégica para os processos de planejamento territorial.

Tanto a política de compras locais das empresas quanto a política de compras governamentais dos diversos níveis federativos são ferramentas importantes para dar suporte à consolidação de tecidos produtivos em territórios que hoje apresentam baixo dinamismo econômico, catalisando dinâmicas de desenvolvimento a partir da materialização dos processos de convergência estratégica mencionados.

Em termos de escala geográfica e hierarquia produtiva, as cidades médias, exercendo a função de polos territoriais, podem abrigar os empreendimentos produtivos e infraestrutura de maior porte, e demandar insumos das cidades menores no seu entorno territorial, onde serão localizados os empreendimentos e equipamentos públicos de menor abrangência.

A capacidade de convergência intra e entre territórios definirá a conectividade entre os projetos. $\mathrm{O}$ conceito de cidades e territórios inteligentes se aplicará aqueles que souberem articular os diversos atores e construírem conjuntamente estratégias concatenadas em diversas escalas territoriais em uma perspectiva multissetorial. Os consórcios públicos são uma possibilidade de contribuição nesse sentido, ainda que haja um longo caminho de aprimoramento de questões regulatórias pela frente. A escala nacional, por sua vez, deve ter o papel de enxergar e coordenar as dinâmicas locais de um ponto de vista macro.

Em diversos territórios no Brasil, já podem ser conhecidas iniciativas produtivas que tomam como ponto de vista as comunidades. Tecnologias e inovações sociais das mais diversas estão sendo desenvolvidas, com uma premissa de responsabilidade socioambiental legítima. Essa visão, de que o bem-estar da comunidade é importante para o sucesso dos empreendimentos, vem crescendo entre as novas gerações, e precisa ser ainda mais estimulado pelas políticas públicas.

Por fim, mas não menos importante, pessoas serão necessárias para difundir esse paradigma e, no caso de regiões ainda pouco integradas, a atração e formação de quadros técnicos capazes de enraizar conceitos e métodos inovadores é de fundamental importância. $\mathrm{O}$ estímulo à pesquisa para desenvolvimento científico e tecnológico deve estar em lugar de destaque na política territorial, a fím de valorizar as riquezas materiais e imateriais de cada lugar. Universidades públicas alinhadas com a estratégia nacional de desenvolvimento de longo prazo tem, nesse sentido, papel altamente relevante, que deve ser defendido e aprofundado.

\section{CONSIDERAÇÕES FINAIS}

O presente artigo discorreu sobre desafios das políticas públicas de desenvolvimento territorial, em especial aqueles relacionados à governança e ao relacionamento institucional nos territórios. Além disso, foram abordados aspectos da pesquisa operacional relacionados, a fim de contextualizar a apresentação de uma ferramenta de estruturação de problemas sociais complexos desenvolvida na COPPE/UFRJ - o CHAP2, que visa à promoção de processos convergentes entre atores dos mais diversos perfis institucionais e filosóficos. Por fim, foi proposta uma agenda de trabalho e pesquisa para futuros projetos que se interessem em avançar na resolução dos desafios do desenvolvimento territorial, para o que foram esboçadas algumas diretrizes para debate.

A ênfase do trabalho foi a necessidade de aprimoramento dos espaços de diálogo e a promoção de uma visão sistêmica, que consolide uma postura de corresponsabilidade pelo desenvolvimento territorial por parte do setor privado, dos governos e da sociedade organizada. Entende-se que a ampla participação dos atores interessados, a integração de ações e o papel do Estado Nacional na coordenação de projetos, para que se harmonizem nas mais diversas escalas, é um caminho importante para o alcance de melhores patamares de desenvolvimento, cuja acepção plena contempla o conceito de sustentabilidade, com equilíbrio entre os aspectos econômico, social e ambiental.

\section{Referências Bibliográficas}

[1] BACELAR de Araujo, Tânia. Por uma Política Nacional de Desenvolvimento Regional. In: Revista Econômica do Nordeste, v. 30, n. 2. Fortaleza: Banco do Nordeste, abr.-jun./1999, pp. 144-161.

[2] BECATTINI, Giacomo. The Marshallian Industrial District as a Socio-economic Notion. in PYKE, F., BECATTINI, G., SENGENBERGER, W. (eds.), Industrial Districts and Interfirm Co-operation, Geneva: International Institute for Labour Studies, 1990, pp. 37-51. 
[3] BOHM, David. Diálogo: Comunicação e redes de convivência. Palas Atena: São Paulo, 2005.

[4] BRASIL. Constituição Federal de 1988. Promulgada em 5 de outubro de 1988. Disponível em http://www.planalto.gov.br/ccivil_03/constituicao/constituição.htm. Acesso em 10/02/2019.

[5] Ministério do Planejamento, Orçamento e Gestão. Secretaria de Planejamento e Investimentos Estratégicos e Centro de Gestão e Estudos Estratégicos. Resumo Executivo. Estudo da dimensão territorial do PPA. Brasília, 2006: SPI/MP.

[6] BUARQUE, Sérgio. et al. (2012) Reflexões e proposições de políticas públicas de desenvolvimento territorial. Brasílía: IICA. Série Desenvolvimento Rural Sustentável, v. 15. Disponível em: http://oppa.net.br/livros/Volume_1_Serie_DRS.pdf . Acesso em 28/09/2018.

[7] CAMPOLINA Diniz, Clélio. Repensando a questão regional brasileira: tendências, desafios e caminhos. In: CASTRO, Ana Célia. (org.). Desenvolvimento em Debate: Painéis do desenvolvimento brasileiro II, v. 3. Rio de Janeiro: Mauad / BNDES, 2002.

[8] CANO, Wilson. Questão regional e política econômica nacional. In: CASTRO, Ana. Célia. (org.). Desenvolvimento em Debate: Painéis do desenvolvimento brasileiro II, v. 3. Rio de Janeiro: Mauad / BNDES, 2002.

[9] ESTELlitA LINS, Marcos e ESTELliTA LINS, Angela. Metacognição e Autoengano. In: ESTELLITA LINS, Marcos e ANTOUN NETTO, Sergio. (orgs). Estruturação de Problemas Sociais Complexos: Teoria da Mente, Mapas Metacognitivos e Modelos de Apoio à Decisão. Rio de Janeiro: Interciência, 2018.

[10] ESTELLITA LINS, Marcos. Paradoxos dos Sistemas Complexos. In: ESTELLITA LINS, Marcos e ANTOUN NETTO, Sergio. (orgs). Estruturação de Problemas Sociais Complexos: Teoria da Mente, Mapas Metacognitivos e Modelos de Apoio à Decisão. Rio de Janeiro: Interciência, 2018 (2018a).

[11] Multiplicidade e Inteligência Emergente. In: ESTELLITA LINS, Marcos e ANTOUN NETTO, Sergio. (orgs). Estruturação de Problemas Sociais Complexos: Teoria da Mente, Mapas Metacognitivos e Modelos de Apoio à Decisão. Rio de Janeiro: Interciência, 2018 (2018b).

[12] . Avaliação Complexa Holográfica de Problemas Paradoxais. In: ESTELLITA LINS, Marcos e ANTOUN NETTO, Sergio. (orgs). Estruturação de Problemas Sociais Complexos: Teoria da Mente, Mapas Metacognitivos e Modelos de Apoio à Decisão. Rio de Janeiro: Interciência, 2018 (2018c).

[13] EVANS, Peter. Constructing the 21 st century developmental state: potentialities and pitfalls. In: EDIGHEJI, O. (org.). Constructing a democratic developmental state in South Africa: Potentials and challenges. HSRC Press. Cape Town, 2010.

[14] FAVARETO, Arílson. Retrato das políticas de desenvolvimento territorial no Brasil. Documento de Trabajo $\mathrm{n}^{\circ}$ 26. Programa Dinámicas Territoriales Rurales. Centro Latinoamericano para el Desarrollo Rural - Rimisp, Santiago, Chile, 2009.

[15] FURTADO, Celso. Formação econômica do Brasil. 22 ed., São Paulo: Editora Nacional, 1987.

[16] GRIFFIN, Douglas. The emergence of leadership. Linking self-organization and ethics. London: Routledge, 2002. 
[17] IBGE. Regiões de influência das cidades 2007. Rio de Janeiro: IBGE, 2008.

[18] MATOS, Marcelo; CASSIOLATO, José Eduardo; LASTRES, Helena; LEMOS, Cristina; SZAPIRO, Mariana. (orgs). Arranjos Produtivos Locais: Referencial, experiências e políticas em 20 anos da Redesist.1a ed. Rio de Janeiro, 2017: E-papers.

[19] MINGERS, John. Realising Systems Thinking: Knowledge and Action in Management Science. Springer, 2006. Capítulo 10

[20] MONTEIRO NETO, Aristides; CASTRO, César.; BRANDÃO, Carlos. Antônio. Desenvolvimento Regional no Brasil: políticas, estratégias e perspectivas. Rio de Janeiro, 2017: IPEA. Disponível em: http://www.ipea.gov.br/portal/images/stories/PDFs/livros/livros/20170213_livro_dese nvolvimentoregional.pdf. Acesso em 01/11/2018.

[21] PAMPLONA, Leonardo. De baixo para cima: o sentido da construção do planejamento para o desenvolvimento. In: Revista Brasileira de Planejamento e Orçamento, v. 1, no 2, 2011, pgs. 21-40, Brasília. Disponível em: http://assecor.org.br/files/6413/5886/3084/rbpo_de_baixo_para_cima.pdf. Acesso em: 05/11/2018.

[22] PORTER, Michael. A Vantagem Competitiva das Nações. Rio de Janeiro, 1993: Campus.

[23] PUTNAM, Robert. Comunidade e Democracia: a experiência da Itália Moderna. Rio de Janeiro:, 2002 Editora FGV. $3^{\mathrm{a}}$ edição.

[24] RODRIK, Dani. Institutions for High-Quality Growth: What Are They and How to Acquire Them. Paper presented at IMF conference, "Second-Generation Reforms", Washington, DC: November 8-9, 1999.

[25] SEN, Amartya. Desenvolvimento como liberdade. Tradução Laura Teixeira Motta. São Paulo: Companhia das Letras, 2005. $5^{\text {a }}$ reimpressão.

[26] ZAOUAL, Hassan. Nova Economia das Iniciativas Locais: uma introdução ao pensamento pós-global. Rio de Janeiro: DP\&A Editora. 2006. 